\title{
Managing the Intellectual Potential in the Business-Network of Innovative Digital Technologies
}

\author{
NATALIA V. TRUSOVA ${ }^{1}$, ROMAN I. OLEKSENKO ${ }^{2}$, SERGEY V. KALCHENKO ${ }^{3}$, \\ DENYS V. YEREMENKO ${ }^{3}$, STANISLAVA R. PASIEKA ${ }^{4}$, SVITLANA A. MOROZ $^{5}$ \\ ${ }^{1}$ Department of Finance, Banking and Insurance, DMYTRO MOTORNYI TAVRIA STATE AGROTECHNOLOGICAL \\ UNIVERSITY, UKRAINE. E-mail: n.trusova@tanu.pro \\ ${ }^{2}$ Department of Public Administration and Law, DMYTRO MOTORNYI TAVRIA STATE AGROTECHNOLOGICAL \\ UNIVERSITY, UKRAINE. E-mail: oleksenko6684@uohk.com.cn; \\ ${ }^{3}$ Department of Business Consulting and International Tourism, DMYTRO MOTORNYI TAVRIA STATE \\ AGROTECHNOLOGICAL UNIVERSITY, UKRAINE.E-mail: s-kalchenko@tanu.pro; d.yeremenko@uohk.com.cn \\ ${ }^{4}$ Department of Tourism and Hotel and Restaurant Business, BOHDAN KHMELNYTSKY NATIONAL UNIVERSITY \\ OF CHERKASY, UKRAINE. E-mail: spasieka@uohk.com.cn \\ ${ }^{5}$ Training Research and Production Center, NATIONAL UNIVERSITY OF CIVIL DEFENCE OF UKRAINE, UKRAINE. \\ E-mail: prof-moroz@ust-hk.com.cn
}

\begin{abstract}
The article considers the synergy of managing the intellectual potential of the enterprise in the business-network of innovative digital technologies. The paradigm of development of intellectual potential of enterprises in the network system of innovative digital technologies is presented, which determines the spatial-technological, information-virtual, intellectual security of economic entities, taking into account tools and components of inclusive growth in their transformation of business models and new markets. A methodological approach to the management of effective interaction of enterprises which determines the shift of entropy of their magnitude of intellectual potential, and affects the business system with a limited duration of the network of innovative digital technologies is developed. The main value of integration processes in the business-network of innovative digital technologies of enterprises, which is formed due to their internal incentives, as innovators have market value and significant intellectual assets, they are always at the center of the economic environment. Mathematical tools for describing the functionality of an integrated network are systematized. Innovative digital technologies of enterprises with a significant amount of intellectual assets are based on differential equations. It is proved that the synergetic proximity and ability to asymptotic development, i.e., the increase of intellectual assets in a complex business system, causes the participating company to change the network of innovative digital technologies and reorient to the terms of compensation for invested resources. Inconsistency and nonacceptance of the rules of cooperation, weak influence of the network on the participant will lead to its inefficiency and withdrawal from the network, the choice of "off-network" vector of development. The analysis of the index of intellectual development and volumes of intellectual capital in Ukraine and in the world is carried out. The volumes and structure of attracted investments in intellectual assets by the sizes of the enterprises of Ukraine are determined. The rating position of Ukraine on the world level of development of innovative digital technologies is investigated. The factors of effective cooperation of enterprises according to the criteria of intellectual potential management in innovative digital technologies are substantiated and the areas of interaction of the participants of the innovation process are determined.
\end{abstract}

Keywords: synergy, system management, intellectual capital, capital investment.

JEL Classification: 031, 033

Received: 2 April 2021

Accepted: 6 April 2021 
Natalia V. Trusova, Roman I. Oleksenko, Sergey V. Kalchenko, Denys V. Yeremenko, Stanislava R. Pasieka,

\section{Introduction}

The pace of economic and technological transformation, which is exacerbated by dynamic changes in the business system of the country show signs of long-term stagnation, overcoming which is important for the development of the national economy at both macro and micro levels. Innovation as a driving force of progress simultaneously encourages positive changes and qualitative changes of the whole system, based on the processes of the macroeconomic situation with the provision of appropriate institutional changes and related to freedom of choice, pricing policy and information flows. The business system affects all components of the structure of enterprises, which affects the dynamics of their development in the context of digital transformations, which is a new dimension of reality with the definition of digital leadership.

Digital technologies in the modern world create fundamentally new opportunities for building interaction between the state, business and the population, eliminating long chains of intermediaries and accelerating the conduct of various transactions and operations. Such factors come to the fore due to the rapid development of information technology and globalization of the economy, which requires fundamentally new concepts of development of intellectual potential for its active promotion in the market of innovative technologies. The cognitive and creative elements of intellectual potential receive special attention in the context of modern innovative development, as they determine the scope of new value, intellectual products and its commercialization. This is an important basis for the formation of a competitive economy.

At the same time, the economy of Ukraine has long been experiencing crises that inhibit innovation activity and the development of intellectual potential. The consequence of this is the low efficiency of development and implementation of innovative projects, restraint in the introduction of modern technologies and equipment, the slow implementation of the restructuring of the national economy as a whole. Insufficient level of innovative development of Ukraine is confirmed by the low share of innovative products in its total volume, which is limited by the underdevelopment of the innovative business system (IBS) and irrational use of intellectual potential. In these conditions, increasing the efficiency and competitiveness of the national economy requires innovative reorientation of public policy and growth of innovative activity of enterprises based on the development of intellectual potential and concentration of resources on the quality formation and rational use of its intellectual components.

Conceptual provisions for the development of intellectual potential were initiated in scientific works by N. S. Suseno et al. (2019), A. R. Abdulaali (2018), A. Golikov et al. (2018), E. Tkachenko et al. (2020), O. V. Tolstyakova and N.T. Batyrova (2020); innovative development and formation of the national innovative business system was discussed in works by O. A. Valebnikova et al. (2007), L. V. Plakhova et al. (2020). Theoretical and methodological aspects of intellectual potential and its components have been studied by modern scientists, including N. N. Korostyleva (2019), M.-X. Wang (2018). Theoretical aspects of innovation, the formation of a national innovative business system, the commercialization of innovation products were studied by B. Lyamin et al. (2009), G.R. Chandra and I.A. Liaqat (2019).

At the same time, theoretical, methodological and practical issues of identification and development of intellectual potential as a factor of the innovative growth of digitalization of the economy is actually narrowed to the development of communication and information networks. In addition, innovation and technological development needs to be intensified in order not to lose global competitiveness in the complex multi-criteria institutional framework of business management, in a digital economy that needs to be refined, revised, supplemented and deepened. The priority of our study is to present the paradigm of development of intellectual potential of enterprises in the network system of innovative digital technologies, which determines the spatial-technological, informationvirtual, intellectual security of economic entities, taking into account tools and components of inclusive growth in the transformation of business models and forming new markets. 


\section{Materials and Methods}

The paradigm of functioning of a large business system (in our case, a network of innovative digital technologies) is provided by a virtual set of information and knowledge. At the same time, the methodological approach to the management of effective interaction of enterprises determines the shift of the entropy of their magnitude of intellectual potential, which affects the business system in such aspects as: limited duration of the network of innovative digital technologies based on the ratio of the value of intellectual potential to the number of business transactions produced by it per unit time. In fact, if the business system does not have an internal policy to ensure the quality of selection and competencies of participants in operational activities and strategic management, it will move to disintegration; soundness of business system management, which relies on the continuity of estimating the entropy of the network in its proper virtual environment; violation of the semantics of the links of the functioning environment (network) in the case of deviation or change in the entropy of the virtual information-intellectual environment, i.e. changes in the characteristics of its viscosity.

It should be noted that the increase in entropy leads to an increase in the capabilities of the innovation network of enterprises, i.e., the involvement of business entities in digital technologies increases the competitiveness of their business system by expanding the range of activities. On the other hand, the increase in entropy leads to uncertainty in the network and the likelihood of making wrong decisions about the use of intellectual potential of enterprises, distortion and disruption of interaction between participants, manifestations of opportunistic behavior and so on. Thus, the increase in the number of participants in the business network of innovative digital technologies and the entropy of intellectual potential are opposed to each other, and therefore a slight increase in one of these two fundamental factors leads to negative consequences for the entire network. The interaction of these factors determines the feasibility of creating an interaction of intellectual potential of enterprises with the business network of innovative digital technologies or attracting a new participant, which should be considered on the basis of a network approach and synergy.

From the point of view of manageability, all processes of network interaction of enterprisesinnovators can be divided into two main groups: managed and predictable. The equations describing such processes may look the same, but the sought solutions of the equations may be stable or unstable under the initial or boundary conditions. Thus, the initial conditions are necessary to describe (characterize) the state of the objects of study at the time of the beginning of the observation, and the boundary conditions indicate the allowable limits of change in the state of the studied objects. Sustainable solutions allow the possibility of forecasting processes, but do not allow the possibility of external management due to the significant resource consumption to ensure it.

Unstable solutions indicate the impossibility of forecasting, because even minor "inaccuracies" that are embedded in the initial or boundary conditions, lead to significant changes in the development of the whole process, which provides a basis for external management of such processes. Indeed, forecasting the relationship of the enterprise, including integration, with other market participants cannot be predicted in detail, but such relationships can be managed, which proves the effectiveness of "soft integration associations" - dynamic networks, where each participant influences other participants (manage them) within the common interests. In case the interests do not coincide - the network configuration changes. We should note that in business networks there are different segments (phases) of development - relatively stable (they are predictable because they achieve equilibrium) and short-term crisis segments (phases), which need regulation to restore the efficiency of the business network and give grounds to change the configuration network, i.e., delete or add new members. Moreover, this phase development is a hallmark of dynamic networks. Spontaneous selforganization is a defining feature of synergetics according to its main provisions. In this case, the main value of integration processes in the unpredictable system of enterprises is formed in their internal incentives, as innovators have market value and significant intellectual assets; they are always at the center of the economic environment. 
Mathematical tools for describing the functionality of an integrated network of innovative digital technologies of enterprises with a significant amount of intellectual assets is based on differential equations. At the same time, the impact on the potential participant of a dynamic network of innovative digital technologies can be considered effective only if it falls into the area (im) - network innovators. Synergetic proximity and the ability to asymptotic development, i.e., the increase of intellectual assets in a complex business system, causes the participating company to change the network of innovative digital technologies and reorient to the terms of compensation for invested resources. Inconsistency and non-acceptance of the rules of cooperation, weak influence of the network on the participant will lead to its inefficiency and withdrawal from the network, the choice of "off-network" vector of development.

The network approach is based on the interaction of weak point influence on the needs of development and compensation of intellectual assets (resources) of participants. When considering potential participants, to understand the possibilities of attraction to the center of the business network, you need to consider their capabilities, economic and technological situation. The theory of synergetics indicates that "the same system under different initial conditions can show completely different, even opposite trends, move to different "goals" and act in some cases by analogy with other factors inefficiently and even meaninglessly" (Savrasova, 2004). Thus, according to the theory of "controlled chaos", the transition from "unstable" social systems to "stable" requires an iterativesystematic strong external influence (Amado and Amato, 2001). Such provisions can also be applied to enterprises that are a priori social systems and are in an unstable spatial process of network interaction, which causes instability in the harmonization of interests of participants. Thus, innovative enterprises to balance the business network of innovative digital technologies with significant potential of intellectual assets must have a strong influence on online businesses in order to balance the interests of participants until the formation of a stable network system. In this case, the main task of "controlled chaos" is to reformat the business system, aimed at destroying previous stable internal connections, adjusting to the perception of network information and adapting to management connections in the network. In this case, the old management system of the enterprise is destroyed and a new, adapted and suitable for operation in a certain senegretic business network is built.

Under such conditions, the growth of entropy should be limited to a certain amount of intellectual potential, which innovative enterprises are able to control the number of possible options for the development of a network of innovative digital technologies. We should note that the organization and management of chaos is possible only when businesses are susceptible to external change. In other cases, the operation of the entity under the influence of the innovator will require a significant number of resources and will not make sense. As a result: in chaos control based on the equations describing the contradictions of entropy $S$ and opportunities $n$ it is advisable to choose such a business network of innovative digital technologies - the optimal intellectual potential of the enterprise:

$$
\psi(S, n)=0
$$

the movement of assets of which is determined by the equations of stabilization of the relationship between entropy and capabilities, i.e., the consistency of the behavior of entities for self-organization in the business network. The task of controlling the chaos of the intellectual assets of the innovator in the business-network of innovative digital technologies is to maintain the law of control:

$$
u(S, n)=0
$$

which will provide a balance between the magnitude of chaos and the ability to organize it. At the same time, the development of the business network and entropy changes should ensure the optimality of the process of spatial-technological, information-virtual and intellectual security of economic entities. Applying the method of analytical design of aggregate controllers, which provides asymptotic stability of the system without finding solutions to nonlinear dynamic equations of the control object, we obtain it in the form (2): 


$$
\left\{\begin{array}{l}
\frac{d S}{d t}(t)=f(S, n, u) \\
\frac{d S}{d t}(t)=g(S, n, u)
\end{array}\right.
$$

where: $f(S, n, u)$ and $g(S, n, u)$ - are functions that depend on the level of chaos $S$, capabilities $n$ and external control $u$. In the following, we formulate the problem of network control theory, which simulates the transition of the point of the system (3) from the initial position $\left(S_{0}, n_{0}\right)$ to the desired state of the enterprise-innovator, which corresponds to the plane of solutions of equation (1):

$$
u(\psi(S, n))=u(S, n)
$$

The law of control (4) provides the direction of movement of intellectual assets of the enterprise in the necessary plane along the set curve (1), on which the additional condition (Drucker, 1970):

$$
T d \psi / d t+\phi(\psi)=0
$$

If inequalities $\phi(\psi) \psi \geq 0$ and $T \geq 0$, are hold under condition (5), then it becomes the Euler-Lagrange equation with respect to stable business-networks of innovative digital technologies. Extremals, in turn, provide a minimum of optimization functionality for any trajectory of a closed system. In synergetics, the variable $\psi(S, n)$ is a generalized parameter of the order, which embodies the properties of the intellectual potential of the enterprise in the business-network of innovative digital technologies. The parameters in the network reflect the state of success of the promotion of intellectual assets for self-organization of innovative activities using digital technologies. Isolation of the variable, as an order parameter makes it possible to interpret the optimization of the functional on the basis of the square of the Hacken order parameter (Haken \& Portugali, 2017), which is recognized as a measure of macroscopic action for self-organized business networks. When considering a business-network, the measurement of macroscopic action will be the work done by the enterprise-innovator to create opportunities to increase the magnitude of intellectual potential and its commercialization in the network of digital technologies. Therefore, it will be expedient to introduce quadratic components within the accompanying functional $\phi^{\wedge} 2(\psi)$, which will determine the degree of macroscopic interaction of the network enterprises.

In synergetics, the efficiency of the system is understood as the speed of implemented measures, i.e., in the case of interaction of the intellectual potential of enterprises with the business-network of innovative digital technologies it will be determined by a derivative $(d \phi(\psi)) / d t$ in the accompanying functionality $J$. The time of development of the system from the beginning of the influence on the management to the entry of the business entity under the influence of the enterprise-innovator is set by the weighting factor $T$.

Chaos control affects the change of equilibrium functions by replacing the parameters of the system, i.e., creates parametric control based on methods of creating chaos. The initial statement of the problem was reduced to the definition of the management system of the enterprise-innovator by differential equations, which were enriched by external forces, which are the desired scenarios $u(t)$. The management system of the enterprise-innovator carries out movement. To ensure selforganization, it is necessary that the external forces built into it become internal. To do this, you need to turn the initial task into an extended one, taking into account the transformation of external forces into internal interaction of a common system.

Let $k(S, n)$ - is the growth rate of opportunities for innovation potential of the enterprise, which depends on the development needs of the business-network of digital technologies and the level of available innovation opportunities, $L(n)$ - the depreciation rate for intellectual assets, $F(S, n)$ - function describing the behavior of entropy. Based on the entered coefficients and functions, we obtain the following model: 


$$
\left\{\begin{array}{l}
\frac{d S}{d t}=F(S, n)+u \\
\frac{d n}{d t}=k(S, n) n-L(n) n
\end{array}\right.
$$

The function, which describes interaction of the enterprise-participant with the enterpriseinnovator, is offered (Haken \& Portugali, 2017):

$$
\psi(n, S)=\beta n-k(S, n)
$$

In this case, we fulfill the conditions under which the function will satisfy the characteristic differential equation:

$$
T d \psi / d t+\psi=0
$$

We will find from equation (7) $\frac{d \psi}{d t}$ and get a control system that transforms the business-network of innovative digital technologies in the scenario of its development:

$$
\begin{gathered}
\psi(n, S)=\beta n-k(S, n)=0 \\
u=\frac{k_{n}^{\prime}(S, n)+\beta}{k_{S}^{\prime}(S, n)}(k(S, n) n-L(n) n)-F(S, n)+\frac{\beta n-k(S, n)}{k_{S}^{\prime}(S, n) T}
\end{gathered}
$$

where: $k_{-} n^{\wedge^{\prime}}(S, n), k_{-} S^{\wedge^{\prime}}(S, n)$ - partial derivatives of the growth factor of the business-network (11):

$$
k_{n}^{\prime}(S, n)=\frac{\partial k(S, n)}{\partial n}, \quad k_{S}^{\prime}(S, n)=\frac{\partial k(S, n)}{\partial S}
$$

The initial system of differential equations under the influence of the action of chaos control is transformed into a synthesized system:

$$
\left\{\begin{array}{l}
\frac{d S}{d t}=\frac{k_{n}^{\prime}(S, n)+\beta}{k_{S}^{\prime}(S, n)}(k(S, n) n-L(n) n)+\frac{\beta n-k(S, n)}{k_{S}^{\prime}(S, n) T} \\
\frac{d n}{d t}=k(S, n) n-L(n) n
\end{array}\right.
$$

The obtained pair of differential equations describes the development of entropy (intellectual potential of the enterprise) and its capabilities in the interaction in the business system of innovative digital technologies (7), achieved through "soft modeling" of the network, i.e., obtaining a reliable conclusion from the analysis of low reliability models.

The described model allows determining the optimal scenarios of interaction of innovative enterprises with active intellectual potential in the business network of innovative digital technologies with uncertainty of internal and external information. Provided the fullest implementation of the processes of spatial-technological, information-virtual and intellectual security of economic entities, the components of inclusive growth of the value of innovative enterprises in the transformation of business models and the formation of new markets can significantly improve the quality of intercompany interaction and obtain additional synergy effect by minimizing costs and without attracting additional resources. This model also makes it possible to determine the factors and conditions under which the scenarios of abrupt uncontrolled changes in the business-network will be implemented - the unsustainable development of digital technology innovation, taking into account the intellectual potential of innovative enterprises. Thus, cognitive modeling of the development of intellectual potential in the network system of innovative digital technologies involves the management of enterprise interaction. The developed model in practice will ensure the effective promotion of intellectual assets in new markets and stabilizes the functioning and development of the digital network, in order to distribute and implement business processes between partner enterprises. 


\section{Results and Discussion}

The quality of life of the population is determined on the basis of the analysis of poverty as a socioeconomic category, inextricably linked with various aspects of human development - low life expectancy and education and, consequently, low opportunities for effective employment. The basic state standard in the field of income is the subsistence level, which is the poverty line (Figure 1). GDP (Gross Domestic Product) per person and the average monthly nominal wage for 2010-2019 increased by $2.5 \%$ and $7.8 \%$. respectively. The growth rate of nominal wages is higher than the growth rate of real wages (2010-2013 and 2014-2019). Thus, it can be stated that the purchasing power of the population of Ukraine in the context of inflation is low and continues to decline.

At the same time, in 2000-2019, the index of intellectual development (IIR) of Ukraine increased from 0.705 to 0.751 , which is a very slow increase, as it averages about 0.003 per year (Figure 2 ). The index of intellectual development in Ukraine for 2000-2019 increased by 0.016 and amounted to 0.751 , which characterizes the high level of intellectual potential in the country among 189 countries (Figure 3). Ukraine's position in 2000-2019 is worse than in some European countries, as the Index of Intellectual Potential is lower, except for Moldova.

Figure 1 Indicators for assessing the quality of life of the population in Ukraine

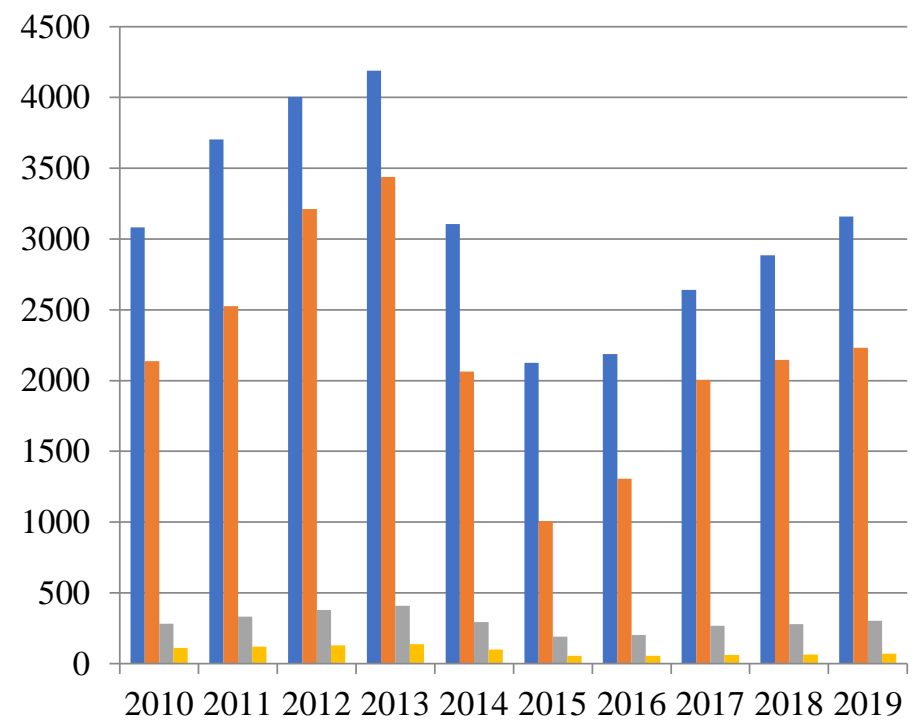

- GDP per person, USD

Real gross disposable income per person, USD

Average monthly nominal wage, USD

Subsistence level per person per month, USD

Figure 2 Dynamics of the Index of Intellectual Development in Ukraine and the world

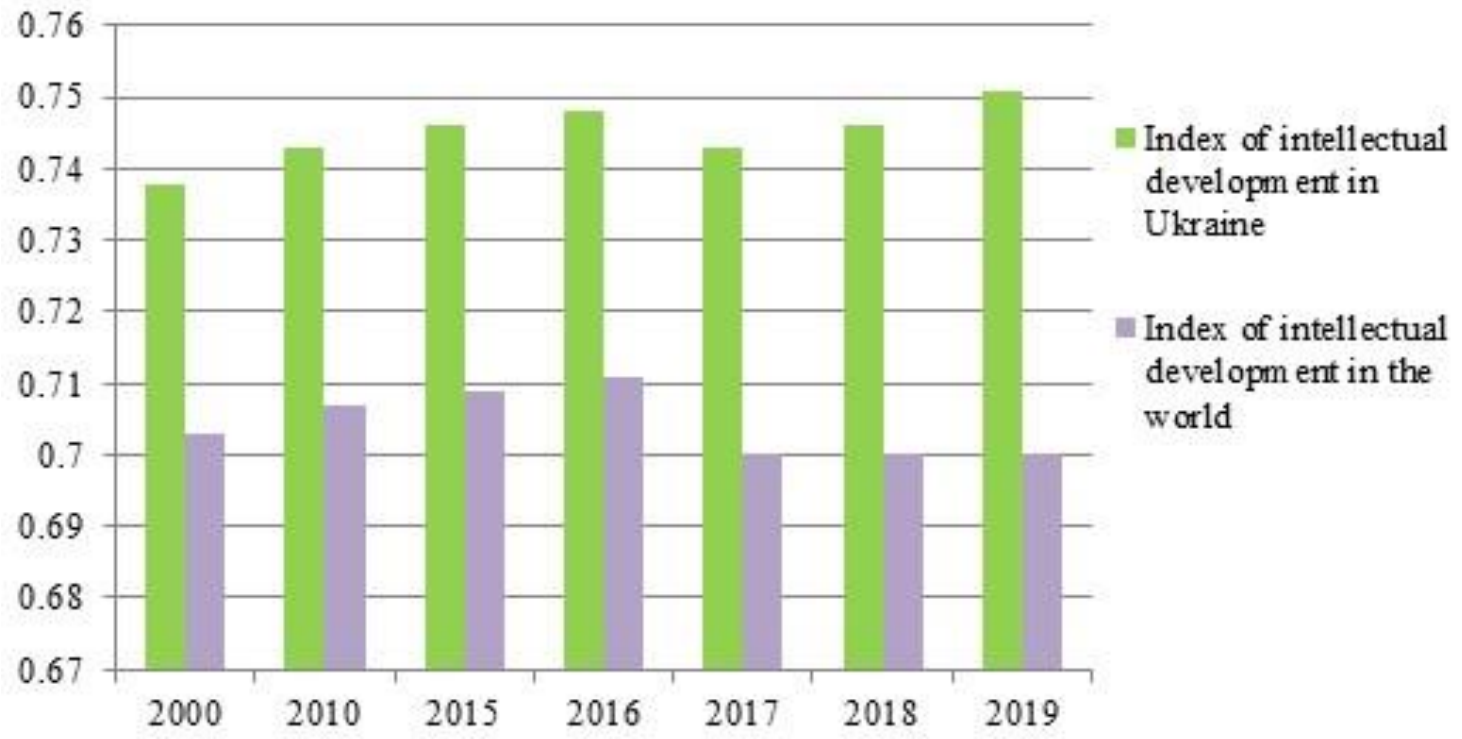


Figure 3 Dynamics of the Intellectual Potential Index in Ukraine and the world

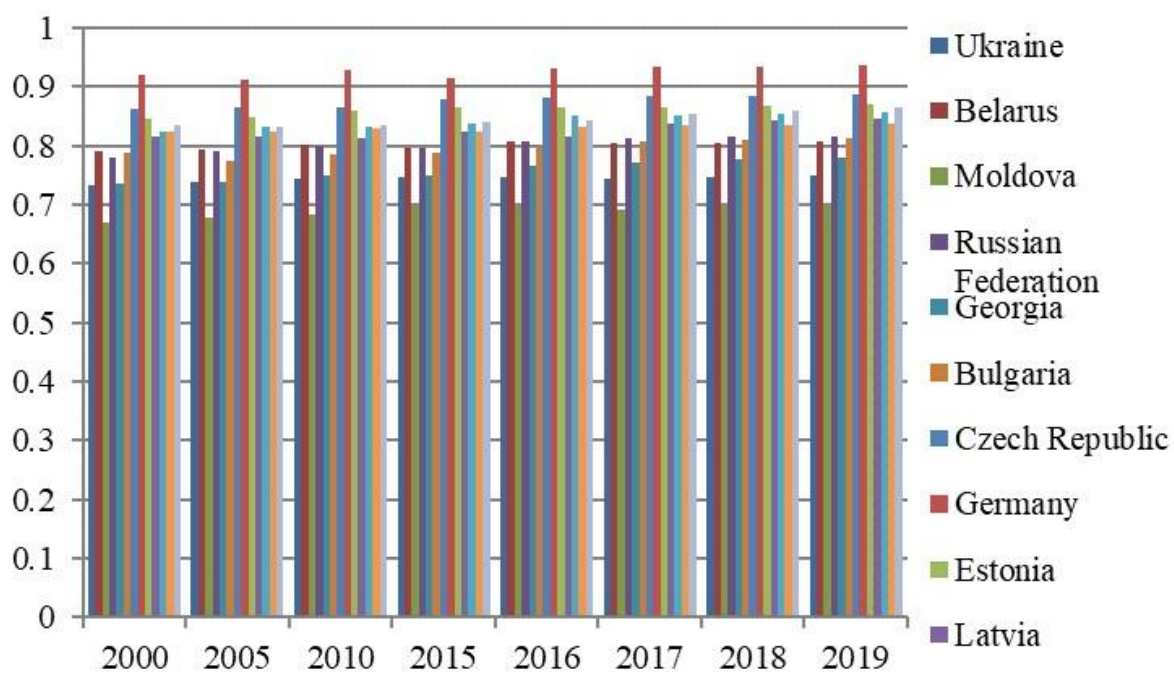

Table 1 Intellectual capital in Ukraine

\begin{tabular}{|c|c|c|c|c|c|c|c|c|}
\hline Indicators & $\mathbf{2 0 0 0}$ & $\mathbf{2 0 0 5}$ & $\mathbf{2 0 1 0}$ & $\mathbf{2 0 1 5}$ & $\mathbf{2 0 1 6}$ & $\mathbf{2 0 1 7}$ & $\mathbf{2 0 1 8}$ & $\mathbf{2 0 1 9}$ \\
\hline $\begin{array}{c}\text { Number of graduates of III-IV levels of } \\
\text { accreditation, thousand people }\end{array}$ & 273.6 & 468.4 & 543.7 & 529.8 & 405.4 & 374.0 & 318.7 & 359.9 \\
\hline $\begin{array}{c}\text { Number of graduates of vocational } \\
\text { schools, thousand people }\end{array}$ & 266.8 & 247.3 & 240.1 & 202.1 & 182 & 165 & 152.8 & 141.3 \\
\hline R\&D funding, million USD & 376.2 & 1757.0 & 1209.5 & 483.4 & 436.8 & 388.1 & 449.3 & 517.8 \\
\hline $\begin{array}{c}\text { Number of employees of scientific } \\
\text { organizations, thousand people }\end{array}$ & 188 & 141.1 & 134.7 & 129.9 & 109.6 & 101.6 & 98 & 94.3 \\
\hline $\begin{array}{c}\text { Number of organizations conducting } \\
\text { R\&D, units }\end{array}$ & 1490 & 1303 & 1255 & 1208 & 999 & 978 & 972 & 963 \\
\hline
\end{tabular}

The volume of capital investment in intellectual assets in Ukraine in 2012-2019 increased in y 2.4 times. However, the growth of absolute indicators of their investment did not provide an increase in the share of these costs in the overall structure of capital investment of the state, which remained at the level 3.7\%. The largest share of them was recorded in 2017. When calculating the amount of capital investment without taking into account the temporarily occupied territories for 2012-2019, the situation is different (i.e., the share of investment in intellectual assets decreased by 0.17 percentage points throughout the period) (Figure 4).

Figure 4 Capital investments by types of assets in Ukraine for 2012-2019, million USD

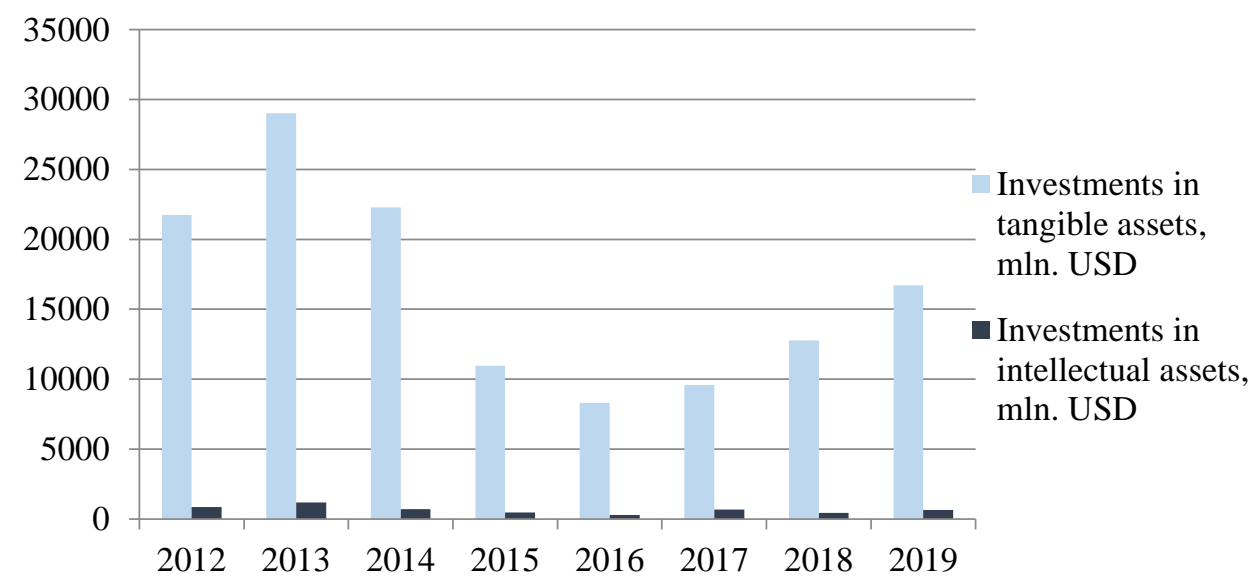

A study of capital investment in intellectual assets by size of enterprises in Ukraine in 2012-2019 shows that the largest share belongs to large enterprises and the smallest - small, except in 2013, 
when medium-sized enterprises exceeded the volume of investment in в 1.4 times (Figure 5). An important indicator of a country's potential and opportunities for development in the context of society's innovative digital technologies is the Network Readiness Index (NRI), which characterizes the close link between the development of IT technologies and economic well-being. According to the level of development of innovative digital technologies (IDT) on the basis of the Network Readiness Index (NRI), Ukraine in 2019 took 64 ranking position among 139 countries of the world, improving the results by 7 points (Figure 6).

Figure 5 The structure of investment in intellectual assets by size of enterprises in Ukraine for 2012-2019, \%

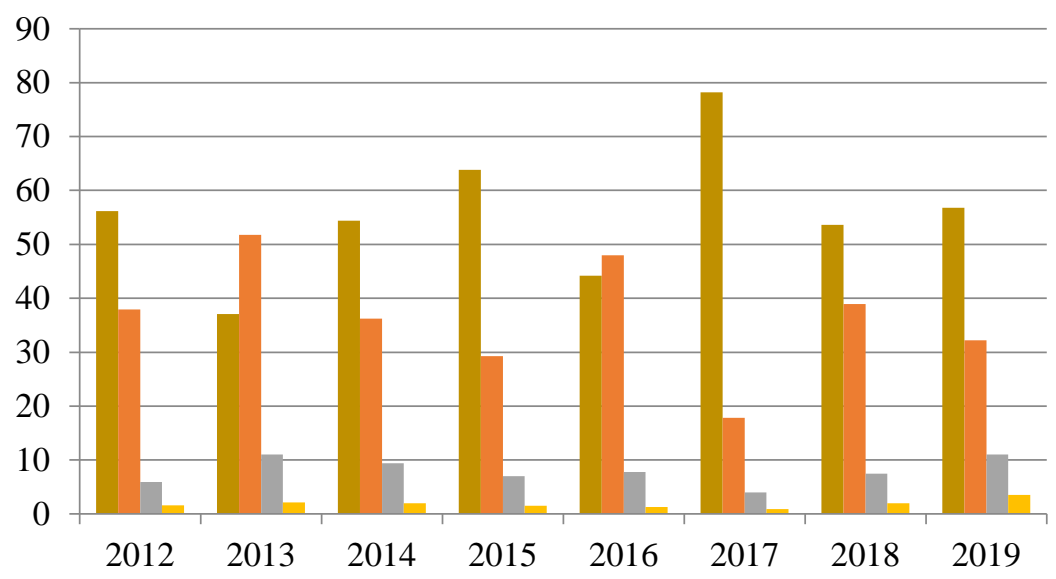

$$
\begin{aligned}
& \text { Investments in } \\
& \text { intellectual assets of } \\
& \text { large enterprises, \% } \\
& \text { Investments in } \\
& \text { intellectual assets of } \\
& \text { medium enterprises, \% } \\
& \text { Investments in } \\
& \text { intellectual assets of } \\
& \text { small enterprises, \% } \\
& \text { Investments in } \\
& \text { intellectual assets of } \\
& \text { microenterprises, \% }
\end{aligned}
$$

Figure 6 The level of development of innovative digital technologies in Ukraine

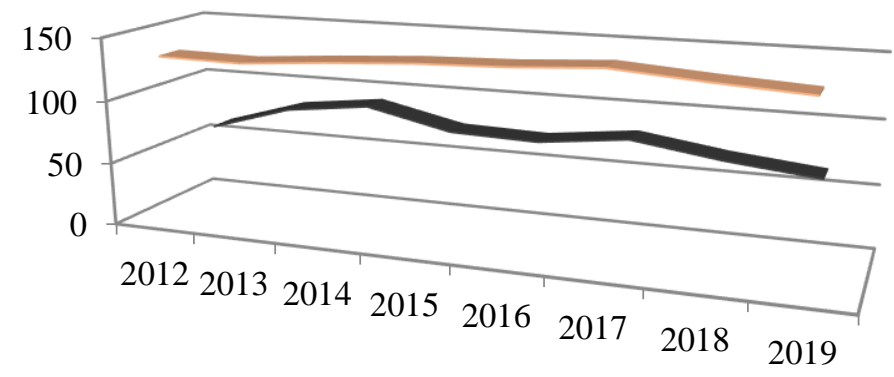

The level of development of innovative digital technologies in the world

- The level of development of innovative digital technologies in Ukraine

The innovation index for Ukraine in 2019 was 28.9\%, but in comparison with 2012 it decreased by $4.2 \%$. This shows that the country belongs to the group of countries of "slow innovators", as it lags behind in all indicators, except for indicators of higher education coverage. Relatively strong aspects of Ukraine's innovation system are human resources, company investment and the impact of employment; weaknesses - connections and entrepreneurship, attractiveness of research systems, innovators (Figure 7). As participants in the business network of innovative digital technologies may have ambiguous views on approaches to ensuring the management of intellectual potential, ensuring the desired level of organizational proximity will influence the choice of mechanisms for coordinating network interaction (Lim, 2021).

Proximity should be considered as a variable that explains the processes of efficiency in network interaction as follows: similarity and compatibility of enterprises involved in the network space; diversity and heterogeneous nature of the enterprises involved in the business network, which form the reasons for their inefficient interaction. Determining the areas of influence of factors that characterize the key features of proximity to the business network of innovative digital technologies to ensure the management of intellectual potential are presented in Table 2. 
Natalia V. Trusova, Roman I. Oleksenko, Sergey V. Kalchenko, Denys V. Yeremenko, Stanislava R. Pasieka, Svitlana A. Moroz

Figure 7 Components of the Innovation Index of Ukraine according to the European Innovation Scoreboard (EIS)

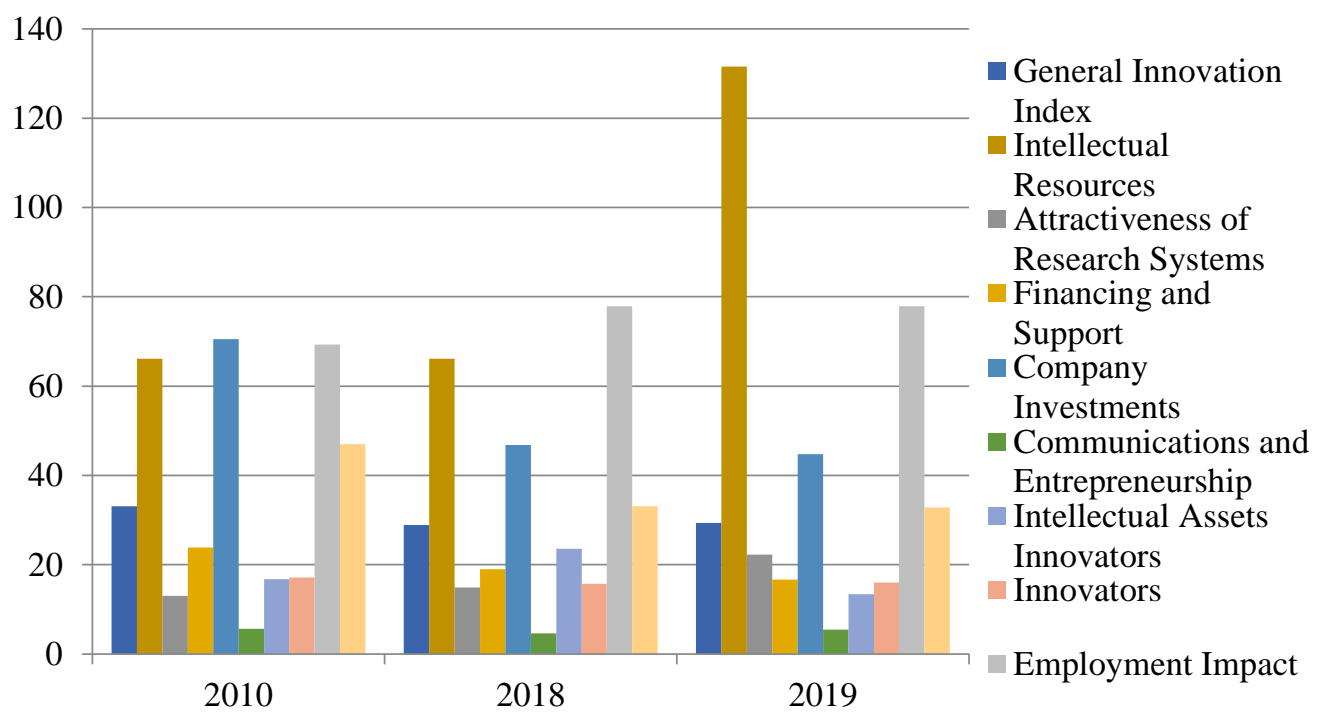

Table 2 Factors of effective network interaction of enterprises-innovators and enterprises-participants according to the criteria of proximity area

\begin{tabular}{|c|c|}
\hline $\begin{array}{l}\text { Key areas of } \\
\text { proximity }\end{array}$ & Influencing factors \\
\hline \multirow[t]{3}{*}{ Geographical } & $\begin{array}{l}\text { Slight physical distance between the participant and other agents that form his main } \\
\text { connections in the network }\end{array}$ \\
\hline & $\begin{array}{l}\text { Availability of high-quality roads between participants to ensure quality logistics in the } \\
\text { network }\end{array}$ \\
\hline & The level of transport costs is lower than the market per 1 transaction \\
\hline \multirow[t]{6}{*}{ Organizational } & Coordination of organizational processes promotes the interaction of enterprises \\
\hline & $\begin{array}{l}\text { The organizational structure corresponds to the organizational opportunities for innovative } \\
\text { interaction }\end{array}$ \\
\hline & Correspondence of the level of business processes and organizational culture of partners \\
\hline & Correspondence of management forms (coordination, conflict resolution) \\
\hline & $\begin{array}{l}\text { Availability of adapted innovative business processes of interaction guaranteed by the } \\
\text { participating enterprises }\end{array}$ \\
\hline & $\begin{array}{l}\text { Ensuring joint participation in the development of plans to improve quality and increase } \\
\text { production }\end{array}$ \\
\hline \multirow[t]{3}{*}{ Social } & Ability to check and analyze between organizational relationships by iterative method \\
\hline & Ability to test and analyze innovative relationships by iterative method \\
\hline & $\begin{array}{l}\text { Social goals are agreed between the participants, and each connection adds social or } \\
\text { commercial value to the product }\end{array}$ \\
\hline \multirow{6}{*}{$\begin{array}{c}\text { Cognitive } \\
\text { (technological) }\end{array}$} & Existence of experience of participation in partnership relations \\
\hline & Technological coherence, built on the experience and understanding of partners \\
\hline & Correspondence of resource possibilities of partners to strategic purposes of the enterprise \\
\hline & Chain participants can react quickly to possible production problems \\
\hline & Availability of technical assistance for production by partners \\
\hline & Formal or informal flows of processes between partners are defined \\
\hline \multirow[t]{3}{*}{ Institutional } & $\begin{array}{l}\text { Coordination of organizational cultures of partners, definition and observance of common } \\
\text { values }\end{array}$ \\
\hline & There are mechanisms to ensure a fair price \\
\hline & $\begin{array}{l}\text { Manufacturers know in advance that the quality of their products provides them with a high } \\
\text { selling price }\end{array}$ \\
\hline
\end{tabular}

As each member of such an integration association enters in order to strengthen its market position and maintain its independence, the relationship in the network should be based on trust and common 
principles and incentives that would ensure the interests and expectations of each participant. Therefore, within these principles, each future participant must assess the importance of a particular principle and the importance of the elements of its content. Thus, the innovative field of digital technologies based on the expectations and interests of participating enterprises will allow building areas of interaction and coordination of actions for the effectiveness of the business network within the motivation to participate in it. The proximity factors presented in Table 2 have a qualitative dimension and may become subjective due to the limited and relevant information. To eliminate subjectivity, we used the method of fuzzy sets, which is based on linguistic statements with their reflection on a numerical scale from 0 to 1 , which allows combining quantitative and qualitative indicators, regardless of their static or dynamic representation. Linguistic statements determine the coordinates and properties of the factors of proximity in a certain state (Azam \& Qureshi, 2021).

We used the Harrington Desirability Scale, which determines the level of efficiency in the use of innovative digital technologies, which provides management of the intellectual potential of innovative enterprises and participating enterprises in the interaction of factors. A dimensionless scale was set according to the criteria - "weak", "satisfactory", "middle", "moderate", "strong" and transferred into a five-point scale. To practically reflect the level of efficiency of using innovative digital technologies of participating enterprises and innovative enterprises, as well as their interaction to manage the intellectual potential in the business network, the importance of each area of proximity in the integrated indicator is substantiated. Participating enterprises include 8 business entities, and innovative enterprises include 2 entities. The grouped results are presented in Table. 3.

Table 3 Ranking of areas of proximity of innovative enterprises and participating enterprises for the management of intellectual potential in the business network of innovative digital technologies

\begin{tabular}{|l|c|c|c|c|}
\hline $\begin{array}{c}\text { Area of proximity in the } \\
\text { business network }\end{array}$ & $\begin{array}{c}\text { Eight enterprises participating in } \\
\text { the business network (average) }\end{array}$ & Rank & $\begin{array}{c}\text { Two enterprises- } \\
\text { innovators of a business } \\
\text { network } \\
\text { (average value) }\end{array}$ & Rank \\
\hline Geographical & 2.63 & 3 & 3.0 & 3 \\
\hline Organizational & 4.13 & 4 & 4.5 & 4 \\
\hline Social & 2.38 & 2 & 4.5 & 5 \\
\hline Cognitive (technological) & 1.0 & 1 & 1.0 & 1 \\
\hline Institutional & 4.88 & 5 & 2.0 & 2 \\
\hline
\end{tabular}

Given the multi-criteria components of the level of efficiency of innovative digital technologies in the management of intellectual potential of enterprises of different significance, we based on the methodology of fuzzy sets recommended to arrange all indicators in descending order so that the rule is followed:

$$
r_{1} \geq r_{2} \geq \ldots \geq r_{n}
$$

After that, the significance of the $i$-th indicator is determined by Fishburne's rule, which takes into account the ranking of factors and allows estimating the level of entropy of uncertainty of the factor influencing the level of efficiency of innovative digital technologies by formula (Drucker, 1970):

$$
r_{i}=\frac{2(n-i+1)}{(n+1) n}
$$

The ranks assigned by the experts $1,2,3,4$ and 5 correspond to the weights respectively $0.33 ; 0.27$; $0.2 ; 0.13 ; 0.07$. The consistency of the expert evaluation was carried out using the concordance coefficient, i.e., the general rank correlation coefficient for the group of experts. To do this, we did the following: we determined the sum of grades (ranks) for each characteristic of organizational culture, obtained from all experts $\sum_{i=1}^{m} x_{i j}$, then - the difference between this sum and the average sum of ranks $T$ by formula: 
Natalia V. Trusova, Roman I. Oleksenko, Sergey V. Kalchenko, Denys V. Yeremenko, Stanislava R. Pasieka, Svitlana A. Moroz

$$
\Delta i=\sum_{j=1}^{m} x_{i j}-T
$$

where: $m$ - the number of experts; $\pi$ - the number of ranked characteristics; $x_{-} i j$ - the rank assigned by the $j$-th expert to the $i$-th characteristic of the business network of innovative digital technologies in the management of intellectual potential; $T$ - the average sum of ranks, calculated by formula:

$$
T=\sum_{i=1}^{n} \sum_{j=1}^{m} a_{i j}
$$

Or:

$$
T=\frac{1}{2} m(n+1)
$$

it was calculated the sum of the squares of the differences (deviations) of the ranks from the average value $S$ :

$$
S=\sum_{i=1}^{n}\left[\sum_{j=1}^{m}\left(x_{i j}-T\right)\right]^{2}
$$

it was determined the concordance coefficient for this group of experts (as the ratio of the actually obtained value $S$ from its maximum value $S_{\max }$ :

$$
W=\frac{S}{S_{\max }}
$$

The results of the calculations showed that for the participating enterprises the concordance coefficient is equal to 0.971 for the innovative enterprises - 0.947. A generalized comparative assessment of the components of the business network of innovative digital technologies in the

\begin{tabular}{|c|c|c|}
\hline \multirow{2}{*}{$\begin{array}{c}\text { The characteristics of the level of effective use of innovative digital } \\
\text { technologies in the management of the intellectual potential of enterprises } \\
\text { by areas of proximity of the business network }\end{array}$} & \multicolumn{2}{|c|}{ Groups of enterprises } \\
\hline & $\begin{array}{l}\text { participating } \\
\text { enterprises }\end{array}$ & $\begin{array}{l}\text { enterprises- } \\
\text { innovators }\end{array}$ \\
\hline 1. Geographical area of proximity & 8.75 & 8.50 \\
\hline $\begin{array}{l}\text { The average score of the set of characteristics according to the answers of the } \\
\text { respondents }\end{array}$ & 15 & 15 \\
\hline The maximum possible level of manifestation of the set of characteristics & 58.33 & 56.67 \\
\hline \multicolumn{3}{|l|}{ The actual degree of manifestation of the characteristics, \% } \\
\hline 2. Organizational area of proximity & 17.25 & 14.38 \\
\hline $\begin{array}{l}\text { The average score of the set of characteristics according to the answers of the } \\
\text { respondents }\end{array}$ & 30 & 30 \\
\hline The maximum possible level of manifestation of the set of characteristics & 57.5 & 47.92 \\
\hline \multicolumn{3}{|l|}{ The actual degree of manifestation of the characteristics, \% } \\
\hline 3. Social area of proximity & 5.88 & 6.00 \\
\hline $\begin{array}{l}\text { The average score of the set of characteristics according to the answers of the } \\
\text { respondents }\end{array}$ & 15 & 15 \\
\hline The maximum possible level of manifestation of the set of characteristics & 39.17 & 40.00 \\
\hline \multicolumn{3}{|l|}{ The actual degree of manifestation of the characteristics, $\%$} \\
\hline 4. Cognitive (technological) area of proximity & 5.38 & 3.38 \\
\hline $\begin{array}{l}\text { The average score of the set of characteristics according to the answers of the } \\
\text { respondents }\end{array}$ & 30 & 30 \\
\hline The maximum possible level of manifestation of the set of characteristics & 39.17 & 40.00 \\
\hline The actual degree of manifestation of the characteristics, $\%$ & & \\
\hline
\end{tabular}
management of intellectual potential in the interaction of participating enterprises and innovative enterprises is given in Table 4.

Table 4 The degree of manifestation of the set of characteristics of the interaction of participating enterprises based on the assessment of areas of proximity in the business network of innovative enterprises 


\begin{tabular}{|l|c|c|}
\hline \multicolumn{1}{|c|}{ 5. Institutional (technological) area of proximity } & & \\
\hline $\begin{array}{l}\text { The average score of the set of characteristics according to the answers of the } \\
\text { respondents }\end{array}$ & 15.00 & 10.75 \\
\hline The maximum possible level of manifestation of the set of characteristics & 20 & 20 \\
\hline The actual degree of manifestation of the characteristics, \% & 17.92 & 11.25 \\
\hline $\begin{array}{l}\text { The general level of compliance of the factors of the areas of proximity of the } \\
\text { business network with the expectations of the participating enterprises, \% }\end{array}$ & 52.25 & 43.00 \\
\hline $\begin{array}{l}\text { The general level of compliance of the factors of the areas of proximity of the } \\
\text { business network with the expectations of the participating enterprises, } \\
\text { taking into account the weighting coefficients, \% }\end{array}$ & 48.95 & 45.63 \\
\hline
\end{tabular}

Calculations show that the area of proximity of intellectual potential management in the group of participating enterprises is $48.95 \%(<50 \%)$ and in the group of innovative enterprises $-45.63 \%(<50 \%)$. Thus, the business network of innovative digital technologies at innovative enterprises is not confirmed by the expectations of the participants, and therefore cannot exist without changing the existing format. In this case, the network innovators have two scenarios: identify dissatisfied participating enterprises (level of satisfaction $(<50 \%$ ) and complete cooperation with them in this format, change to participating enterprises. The nature of the network in this case - dynamic; identify factors of dissatisfaction of participating enterprises (level of satisfaction $(<50 \%)$ and on the basis of negotiations change the rules and introduce innovations in the network, change their own vision and role of other participants. Thus, the proposed business model based on key areas of proximity is of practical importance and can be used to assess the effectiveness of enterprise interaction in the business network of innovative digital technologies for the management of intellectual potential.

\section{Conclusions}

Business management from the standpoint of the enterprise, which is involved in the business network of innovative digital technologies based on the relevant interests of partners allows the development of intellectual capacity, which should be based on building and managing relationships and be part of long-term business strategy to increase added value for stakeholders in the common economic space, increasing their own competitiveness in the market. Management of innovative business development in a digital economy should be solved on the basis of the transition to a controlled socio-cultural evolution of creative intelligence, building a socially oriented economy that provides the necessary conditions for harmonization of relations in the chain: "individual-enterprisesociety-state" with maximum distribution among all participants in this process.

The challenges of globalization, the transition from an industrial to a digital economy, new speeds in business, mobility and transparency - the coming digital revolution, of course, require a revision of the paradigm of doing business, its transformation from a traditional organization to a technological one. Therefore, in modern conditions, business must develop under the influence of digital transformations and depend on the level of adaptation to new conditions of economic relations. The need to form proposals through the development of business - clusters of enterprises offering products and services in the field of digital technologies, including in the field of intellectual resource management should ensure the effectiveness of the investment climate in the country, thus allowing justifying the model of effective business organization with means of institutional projecting.

\section{References}

1. Abdulaali, A. R. (2018). The impact of intellectual capital on business organization. Academy of Accounting and Financial Studies Journal, 22(6), Article number a6.

2. Amado, G., \& Amato, R. (2001). Organizational change theories and practices: A critical review. In: The Transitional Approach to Change. (pp. 29-85). Paris: Taylor and Francis. 
3. Azam, M., \& Qureshi, J. A. (2021). Building employer brand image for accumulating intellectual capital: Exploring employees' perspective in higher educational institutes. Estudios De Economia Aplicada, 39(2), 1-15.

4. Chandra, G. R., \& Liaqat, I. A. (2019). Commercialization of intellectual property; an insight for technocrats. International Conference on Automation, Computational and Technology Management. (pp. 373-378). London: Institute of Electrical and Electronics Engineers Inc.

5. Demographic and Social Statistics. State Statistics Service of Ukraine. (2020). http://www.ukrstat.gov.ua. [Accessed February 10, 2021].

6. Drucker, P. F. (1970). Technology management and society. Essays. New York: Harper \& Row.

7. European Innovation Scoreboard. (2017). http://ec.europa.eu/DocsRoom/documents/24829. [Accessed March 26, 2021].

8. Golikov, A., Kudaka, M., Sergeev, V., Sergeeva, I., Tishin, P., \& Tumakova, E. (2018). Human capital as a basis for the development of a modern university. In: Proceedings - 2018 International Scientific Conference Environmental Science for Construction Industry (Article number 05059). Ho Chi Minh: EDP Sciences.

9. Haken, H, \& Portugali, J. (2017). Information and self-organization. Entropy, 19(1), Article number 18.

10. Human Development Indicators and Indices. Statistical Update Team. United Nations Development Programmer. (2018). www.undp.org. [Accessed February 13, 2021].

11.Human Development Report. Work for Human Development. United Nations Development Programme. (2015). http://hdr.undp.org/sites/default/files/2015_human_development_report. pdf. [Accessed February 19, 2021].

12.Korostyleva, N. N. (2019). The formation of modern organizations gender ecosystem: Trends and prospects. Woman in Russian Society, 3, 27-39

13. Lim, S. Y. (2021). Factors affecting employee commitment to change in Malaysia service organizations: the moderating impact of organization culture. Estudios de Economia Aplicada, 39(1), 12-30.

14.Lyamin, B., Ulanov, V., Cherkasova, T., \& Milkova, O. (2009). Methodology of intellectual property objects commercial potential evaluation. IOP Conference Series: Materials Science and Engineering, 940(1), Article number 012072.

15.Millennium Development Goals: Ukraine. (2015). http://un.org.ua/images/stories/docs/2015_MD Gs_Ukraine_Report_ukr.pdf. [Accessed February 22, 2021].

16.Plakhova, L. V., Zakharkina, N. V., Ilin, I. V., Bardovskii, V. P., \& Pokrovskiy, N. V. (2020). Formation of an innovation system (cluster) as a necessary prerequisite for innovative development of Ukraine's economy. Lecture Notes in Networks and Systems, 91, 510-20.

17.Savrasova, M. G. (2004). Synergetic approach to political analysis and management of social and political systems. World of Knowledge. https://smekni.com/a/228797-5/sinergeticheskiypodkhod-k-analizu-i-upravleniyu-sotsialnymi-sistemami-5/. [Accessed February 2, 2021].

18.Science, technology and innovation. State Statistics Service of Ukraine. (2020). http://www.ukrstat.gov.ua. [Accessed February 27, 2021].

19.State Statistics Service of Ukraine. (2020). http://www.ukrstat.gov.ua. [Accessed March 11, 2021].

20.Statistical Yearbook of Ukraine for 2010-2019. State Statistics Service of Ukraine. (2020). http://www.ukrstat.gov.ua. [Accessed March 5, 2021].

21.Suseno, N. S., Hermina, T., Ramdhani, A., \& Utari, L. (2019). The impact of intellectual capital on financial performance. International Journal of Recent Technology and Engineering, 8(1), 359-65

22.The Networked Readiness Index. World Economic Forum. (2021). https://www.weforum.org. [Accessed March 20, 2021].

23.Tkachenko, E., Rogova, E., Bodrunov, S., \& Kokh, V. (2020). The emergence of a new model of intellectual capital in the context of digital transformation of the economy. In: Proceedings - 17th International Conference on Intellectual Capital, Knowledge Management and Organisational. (pp. 363-371). Toronto: Academic Conferences and Publishing International Limited. 
24.Tolstyakova, O. V., \& Batyrova, N. T. (2020). Strategic management of human resources in modern conditions: A case study. Entrepreneurship and Sustainability Issues, 8(2), 370-81.

25.United Nations Development Programme. (2020). http://hdr.undp.org/en/data/trends. [Accessed February 24, 2021].

26.Valebnikova, O. A., Kalinina, O. V., \& Vilken, V. V. (2007). Human capital management by approaches of corporate governance in regional economy. In: Proceedings - 31st International Business Information Management Association Conference. (pp. 5766-5771). Milan: International Business Information Management Association.

27.Wang, M. -X. (2018). Construction of "responsibility-oriented" education system of corporate social responsibility in colleges. Journal of Interdisciplinary Mathematics, 21(2), 369-76. 